

\title{
Comparative study of temporal decorrelation at P, L and C-bands: first insights from the tropiscat-2 experiment
} Essebtey Salma El Idrissi, Ludovic Villard, Pierre Borderies, Thierry Koleck, Benoît Burban, Thuy Le Toan

\section{- To cite this version:}

Essebtey Salma El Idrissi, Ludovic Villard, Pierre Borderies, Thierry Koleck, Benoît Burban, et al.. Comparative study of temporal decorrelation at P, L and C-bands: first insights from the tropiscat-2 experiment. Mediterranean and Middle-East Geoscience and Remote Sensing (M2GARSS), Mar 2020, Tunis, Tunisia. 10.1109/M2GARSS47143.2020.9105253 . hal-02917413

\section{HAL Id: hal-02917413 \\ https://hal.science/hal-02917413}

Submitted on 19 Aug 2020

HAL is a multi-disciplinary open access archive for the deposit and dissemination of scientific research documents, whether they are published or not. The documents may come from teaching and research institutions in France or abroad, or from public or private research centers.
L'archive ouverte pluridisciplinaire $\mathbf{H A L}$, est destinée au dépôt et à la diffusion de documents scientifiques de niveau recherche, publiés ou non, émanant des établissements d'enseignement et de recherche français ou étrangers, des laboratoires publics ou privés. 


\title{
COMPARATIVE STUDY OF TEMPORAL DECORRELATION AT P, L AND C-BANDS: FIRST INSIGHTS FROM THE TROPISCAT-2 EXPERIMENT
}

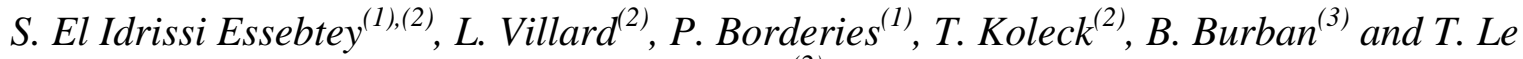 \\ Toan $^{(2)}$ \\ (1) ONERA/DEMR, Université de Toulouse, Toulouse, France \\ (2) Centre d'Etudes Spatiales de la BIOsphère (CESBIO), UMR UPS-CNRS-IRD-CNES, Toulouse, France \\ (3) Ecologie des Forêts de Guyane, (EcoFog) UMR AgroParisTech-CIRAD-INRA-CNRS-Université de Guyane, \\ Université des Antilles, Kourou, Guyane Française
}

\begin{abstract}
Following the past TropiScat and AfriScat tower-based scatterometer experiments conducted as part of the European Space Agency (ESA) BIOMASS mission preparation activities, a follow-up experiment referred to as TropiScat-2 has been undertaken since March 2018 in French Guiana. The main objectives of this new campaign consist in extending the previous time series at $\mathrm{P}$ and $\mathrm{L}$ bands, and also in investigating the possible synergies between $\mathrm{P}, \mathrm{L}$ and C-band measurements thanks to the quasi-simultaneous multifrequency acquisitions provided by the new instrument. In this paper, the differences between temporal decorrelation at $\mathrm{P}, \mathrm{L}$ and C-bands are specifically analyzed based on a 67-day time series dating back to early August 2018. This study confirms previous results conducted at $\mathrm{P}$ and L-bands, with a specific focus here on the importance of the diurnal cycles and on the updated acquisition scenarios for the upcoming BIOMASS mission. Interestingly, this study also reveals the diurnal cycles at C-band, although the coherence values are much lower than those at $\mathrm{P}$ and L-bands. In addition to enhancing scientific insights regarding our understanding of microwave interactions, this study provides key figures for the design of new satellite missions.
\end{abstract}

Index Terms - Temporal decorrelation; P, L, Cbands; Time series; Tower-based scatterometer; Tropical dense forests;

\section{INTRODUCTION}

Time series in remote sensing are often determinant to disentangle the possible ambiguities between the multiple causes behind signal variations, making revisit and continuity of time series highly important. Although limited by a rather small footprint (typically about 1 ha), tower based remote sensing instruments enable a top view of a given region of interest, and thereby allow to mimic observation geometry from space, but with the core advantage of making possible a wide range of quasi-continuous and quasisimultaneous measurements, together with in situ auxiliary data. As an example in the context of the ESA BIOMASS mission preparation activities, we can refer to the TropiScat [1] and AfriScat [2] experiments, respectively conducted in French Guiana (2011-2014) and Ghana (2015-2017). Both experiments were dedicated to tropical dense forests (primary objective of BIOMASS), and provided key results regarding the signal variability at $\mathrm{P}$ and L-bands, and particularly about temporal decorrelation [3] which is a core variable for the design of mission revisit and acquisition time [4]. More recently, a similar experiment has been undertaken to address these questions in the case of a boreal forest [5], considering also C-band acquisitions in addition to the $\mathrm{P}$ and Lband ones. Indeed, thanks to the stronger microwave penetration through such forests especially under frozen conditions that are also very favorable to limit temporal decorrelation [6], the sensitivity of C-band backscatter may be exploited and related to physical properties of the forest $[7 ; 8]$. However, the use of C- 
band to provide relevant information in the case of tropical forests is less obvious. This situation can first be explained by the lack of data in comparison to areas at higher latitude where the revisits related to heliosynchronous orbits are more frequent. Moreover, canopies in the tropics are denser and vegetation cover fraction is higher resulting in a stronger attenuation and weaker image contrast. Finally, the phenology of the different tree species in tropical forests is much more diverse and poorly known [9]. Indeed, this phenology cannot be characterized by strong seasonal changes such as freeze/thaw events, leaf-on/leaf-off or even more progressive Leaf Area Index (LAI) changes as for temperate forests $[10,11]$.

In a recent published paper we focused on the investigation of C-band temporal decorrelation at various time scales in the case of a tropical forest [12]. This study revealed that C-band coherences can reach higher than expected values during nighttime and that their evolution can be explained not only by convective winds but also by evapotranspiration. These promising results suggest further analysis of Cband measurements over tropical forests in parallel with those at $\mathrm{P}$ and L-bands in order to evaluate the possible synergies between these three bands and thereby to better exploit the future BIOMASS mission's P-band data.

With regard to all these concerns, we propose in this paper to exploit measurements of a 67-day time series from TropiScat-2 campaign, in order to analyze the differences between temporal decorrelation at $\mathrm{P}, \mathrm{L}$ and C-bands. Next section focuses on a concise description of the experiment, while a brief recall of the coherence calculation formula is provided in section 3 . before presenting some results in section 4 . and then drawing a conclusion of the study in section 5 .

\section{DESCRIPTION OF THE EXPERIMENT}

As introduced above, a similar P and L-band antenna array as for the previous TropiScat and AfriScat campaigns has been installed on the west side at the top of the Guyaflux (about $55 \mathrm{~m}$ high) [13]. We recall that this antenna array is made up of a set of 20 antennas forming 17 pairs, covering all 4 polarization channels (VV, HH, VH, HV) and providing a vertical imaging capability (tomography). Measurements cover the two bands 400-600 MHz (P-band) and 800-1000 $\mathrm{MHz}$ (low L-band). To extend the measurements to Cband, a new Vector Network Analyzer (VNA) (Rhode\&Schwarz ZNL-6, see www.rohdeschwarz.com) has been installed. Six new antennas dedicated to the C-band have been also set up at the VV polarization and equally split between the west and the northeast sides of the tower (see Fig. 1). Cband acquisition is segmented into three sub-bands of $200 \mathrm{MHz}$ starting from $5.2 \mathrm{GHz}$ (to be named A, B, C). Full acquisition cycles are performed every 15 minutes thanks to the radio frequency switches that sequentially route the signal between each receivetransmit pair and the VNA.



Fig. 1 Picture of the $\mathrm{P}$ and L-band antenna array (top) and the C-band antennas (bottom) with a scheme of the tower and the VNA.

\section{COHERENCE COMPUTATION}

Considering that data acquisition from the VNA is in the frequency domain, the processing consists first in an inverse fast Fourier transform to convert the measurements into the time domain. The resulting range impulse responses can then be used to compute 
the temporal coherence, for a given spatial range (from range gates $i_{\min }$ to $i_{\max }$ ), between the complex responses noted $\mathrm{S}_{\mathrm{t} 1}$ and $\mathrm{S}_{\mathrm{t} 2}$ acquired at two different times $t_{1}$ and $t_{2}$, as detailed through the following formula:

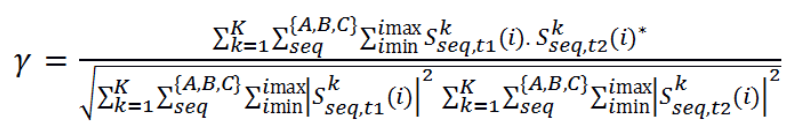

where ' $i$ ' is the range index between $i_{\min }$ and $i_{\max }$, and ' $k$ ' to cover all the antenna pairs. The index 'seq' refers to the consecutive sequences $\mathrm{A}, \mathrm{B}, \mathrm{C}$ within a same acquisition cycle, used only for the C-band processing.

\section{FIRST RESULTS}

In order to better understand and investigate the evolution of temporal decorrelation at $\mathrm{P}, \mathrm{L}$ and $\mathrm{C}$ bands, we consider in this study all 18-day sub-series based on a 67-day time series dating back to August $1^{\text {st }}$ 2018. For each sub-series, we set the reference time for the coherence computation at 6AM on the first day and then calculate the coherence of all measurements with respect to that reference. We then plot the resulting coherences of all sub-series on an 18-day scale as shown in Fig. 2, where the line curves represent the medians of the 50 coherences for each temporal baseline bounded by an outer envelope that defines the first and third quartiles. The choice of this computation approach is based on the acquisition scenarios of the future BIOMASS mission. Indeed, BIOMASS acquisitions are planned for dawn and dusk (6AM/6PM) with a revisit cycle of 18 days. On the three curves we can notice a diurnal cycle of the coherences with a high peak every day around 6AM. P-band coherences are globally very high up to 18 days especially around 6AM. Indeed, the median is higher than 0.8 during this time of day. Regarding the L-band, the dynamics of the coherences is more important as indicated by the width of the envelope representing the $1^{\text {st }}$ and $3^{\text {rd }}$ quartiles but the median remains higher than 0.6 for measurements acquired around 6AM up to 18 days. On the other hand, C-band coherences are lower but still form a diurnal cycle. Interestingly, the median of the coherences calculated at 6AM is higher than 0.2 up to a temporal baseline of about 3 days and its corresponding $3^{\text {rd }}$ quartile is higher than this same value up to more than 10 days. These results emphasize the temporal evolution of changes in the source of the scattering either for small forest components, which are subject to movement, at high frequencies, or changes at a larger scale at low frequencies.

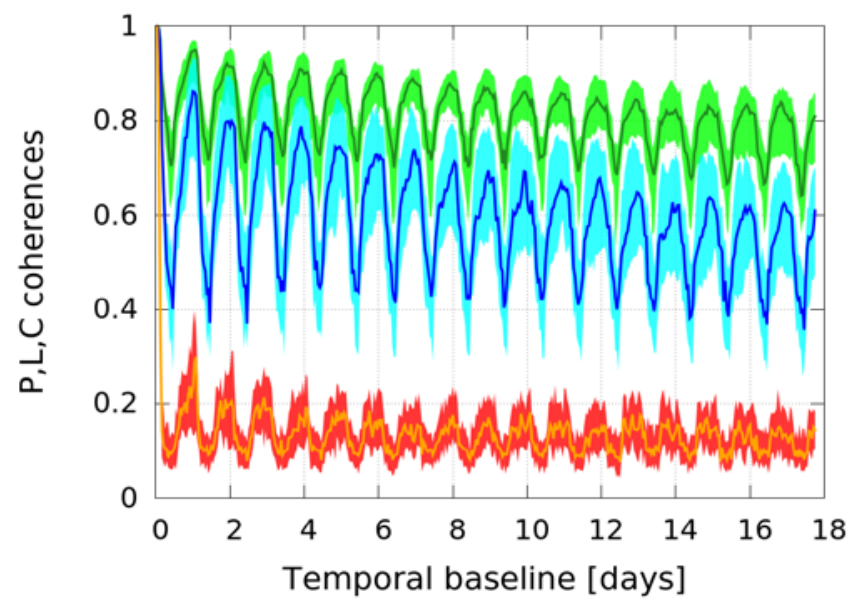

Fig. 2 Evolution of temporal coherences from $15 \mathrm{mn}$ to 18 days considering reference time at 6AM. The green, blue and orange lines correspond respectively to the medians of $\mathrm{P}, \mathrm{L}$ and $\mathrm{C}$-bands coherences, and the indicated lower and upper bound refer to the first and third quartiles derived from all the acquisitions matching a specific temporal baseline.

\section{FIRST CONCLUSIONS AND FURTHER WORK}

Based on the recent acquisitions from the TropiScat-2 experiment, this work highlights the differences between temporal decorrelation at P, L and C-bands. In addition to the consolidation of previous results at $\mathrm{P}$ and L-bands, this work demonstrates that significant coherences can be reached at C-band for longer intervals than the expected few seconds or minutes, and that the diurnal cycles can be observed up to 18 days. Further work will be dedicated to a more quantitative assessment based on statistical analysis which can also serve for predictions within the framework of acquisition scenarios related to the upcoming missions using P-band (BIOMASS), L-band (ALOS-4, NiSAR) and candidate tandem or geostationary missions at C-band (Stereoid, G-Class). Moreover, the analysis of longer time series including a larger range of environmental conditions driven by the rainy and dry seasons will also enable to strengthen 
the physical explanations of water content and convective winds effects on temporal decorrelation.

\section{ACKNOWLEDGMENTS}

The authors would like to thank the French national space agency (CNES) for funding the experiment and the associated research activities as part of the TOSCA research program. The authors are also very thankful to all the people at Ecofog (Laboratoire d'Ecologie des Forêts de Guyane, Kourou) who are contributing to the success of the Paracou research station.

\section{REFERENCES}

[1] A. Hamadi, P. Borderies, C. Albinet, et al. Temporal coherence of tropical forests at P-band: Dry and rainy seasons. IEEE Geoscience and Remote Sensing Letters, 2015, vol. 12, no 3, p. 557-561.

[2] AfriScat Final Report, ESA CONTRACT $\mathrm{N}^{\circ} 4000111758 / 14 / \mathrm{NL} / \mathrm{FF} / \mathrm{GP}$

[3] A. Hamadi, L. Villard, P. Borderies, et al. Comparative Analysis of Temporal Decorrelation at P-Band and Low L-Band Frequencies Using a Tower-Based Scatterometer Over a Tropical Forest. IEEE Geoscience and Remote Sensing Letters, 2017, vol. 14, no 11, p. 1918-1922.

[4] T. Le Toan, S. Quegan, et al. The BIOMASS mission: Mapping global forest biomass to better understand the terrestrial carbon cycle. Remote sensing of environment, 2011, vol. 115, no 11, p. 2850-2860.

[5] L.M.H. Ulander, A. R. Monteith, et al. Multiport Vector Network Analyzer Radar for Tomographic Forest Scattering Measurements. IEEE Geoscience and Remote Sensing Letters, 2018, no 99, p. 1-5.

[6] J.I.H. Askne, P.B.G. Dammert, L.M.H. Ulander, et al. C-band repeat-pass interferometric SAR observations of the forest. IEEE Transactions on Geoscience and Remote Sensing, 1997, vol. 35, no 1, p. 25-35.

[7] W. Wagner, J. Vietmeier, et C. Schmullius. Information content of ERS SAR interferometric products for forest classification in SIBERIA: a case study over the Bolshemurtinskii forest enterprise. In: Geoscience and Remote Sensing Symposium 2000. p. 444-446.

[8] M. Santoro, J. Askne, G. Smith, et al. Boreal forest monitoring with ERS coherence. In: Proc. ERS-Envisat Symposium. 2000. p. 16-20.

[9] J. Wu, L.P. Albert, A.P. Lopes, et al. Leaf development and demography explain photosynthetic seasonality in
Amazon evergreen forests. Science, 2016, vol. 351, no 6276, p. 972-976.

[10]C. Proisy, E. Mougin, A. Lopes, et al. Usefulness of ERS coherence time series for monitoring the vegetation cycle of a mixed deciduous forest. Proc. ERSENVISAT symposium, Gothenburg. 2000. p. 16-20.

[11] P-L. Frison, B. Fruneau, S. Kmiha, et al. Potential of Sentinel-1 Data for Monitoring Temperate Mixed Forest Phenology. Remote Sensing, 2018, vol. 10, no 12, p. 2049.

[12]S. El Idrissi Essebtey, L. Villar, P. Borderies et al. Temporal Decorrelation of Tropical Dense Forest at CBand: First Insights From the TropiScat-2 Experiment. IEEE Geoscience and Remote Sensing Letters, 2019.

[13] Guyaflux description: https://paracou.cirad.fr/website 